\title{
Behavioural and cognitive effects of oligofructose-enriched inulin in rats
}

\author{
Michaël Messaoudi ${ }^{1}$, Pascale Rozan ${ }^{1}$, Amine Nejdi $^{1}$, Sophie Hidalgo ${ }^{1}$ and Didier Desor ${ }^{2}$ \\ ${ }^{1}$ ETAP - Ethologie Appliquée, Technopôle de Nancy-Brabois, 13 rue du Bois de la Champelle, 54500 Vandoeuvre-lès-Nancy, France \\ ${ }^{2}$ Laboratoire de Neurosciences Comportementales, Faculté des Sciences, Université Henri Poincaré, 54500 Vandoeuvre-lès-Nancy, \\ France
}

\begin{abstract}
The behavioural and cognitive effects of oligofructose-enriched inulin at the doses of 5 and $10 \%$ in the diet, orally ingested daily during 2 weeks, were investigated using a functional observational battery $(\mathrm{FOB})$ and the light extinction test in male Wistar rats. Control rats received a standard diet and were tested in the same test situations. The behavioural effects were assessed $2 \mathrm{~d}$ before and $14 \mathrm{~d}$ after the beginning of the treatment period and the cognitive effects were investigated after the administration period by lever-pressing activity and learning discrimination using the light extinction test paradigm. In general, the study demonstrated that oligofructose-enriched inulin at $5 \%$ in the diet, and particularly at $10 \%$ in the diet, caused relaxing-like effects, stimulated and increased the general activity and interest of the rats to the test environment. In addition, both doses of oligofructose-enriched inulin showed significant effects on learning discrimination in male rats, in comparison with the control diet. These results suggest that oligofructose-enriched inulin, particularly at the dose of $10 \%$, improves cognitive performances in the light extinction test and the well-being of male rats using the FOB.
\end{abstract}

Oligofructose-enriched inulin: Cognition: Learning: Light extinction test: Rat

Inulin-type fructans are composed of $\beta$-D-fructanoses attached by $\beta-2-1$ linkages. They constitute a group of oligosaccharides derived from sucrose that are isolated from natural vegetable sources such as chicory (Roberfroid, 1999). Product with a degree of polymerisation (DP) from 2 to $60+$ is called inulin. Oligofructose is produced by partial enzymatic hydrolysis of inulin and defined as $\mathrm{DP}<10$. Oligofructose-enriched inulin (Raftilose ${ }^{\circledR}$ Synergy1) is a mixture of chicory long-chain inulin and oligofructose.

Inulin and oligofructose are interesting for the food industry to improve organoleptic characteristics of food. Their incorporation upgraded taste and mouth-feel in a wide range of applications. Oligofructose is highly soluble and has technological properties closely related to those of sugar and glucose syrups (Franck, 2002).

But in addition they have a series of important nutritional properties that include a prebiotic effect, an improvement of mineral absorption, a regulation of hepatic lipogenesis and reduction of the risk of cancer and inflammatory bowel diseases. All these properties are reviewed in detail in the other papers of this supplement.

The aim of the present report is to test the hypothesis that the beneficial effects on health of oligofructose could change the general behaviour of rats and their cognitive performances. Thus studies were performed to assess the behavioural and cognitive effects of oligofructose-enriched inulin at the doses of 5 and $10 \%$ in the diet, orally ingested daily during 2 weeks, using a functional observational battery (FOB) and the light extinction test in male Wistar rats.

\section{Material and methods}

Animals

Eighteen male Wistar rats AF EOPS (Centre Charles River Laboratories, St-Germain sur 1'Arbresle, France) aged $60 \mathrm{~d}$ were used. On receipt, the rats were housed in groups of two in $48 \mathrm{~cm} \times 27 \mathrm{~cm} \times 20 \mathrm{~cm}$ polycarbonate cages (UAR, Epinay-surOrge, France) in stable conditions of humidity $(60 \pm 5 \%)$ and temperature $\left(22 \pm 1{ }^{\circ} \mathrm{C}\right.$ ) and allowed free access to food (food pellets M20; Dietex, Saint Gratien, France) and tap water until the time of the experiment. Animals were maintained on a $12 \mathrm{~h}$ light: $12 \mathrm{~h}$ dark cycle (lights on 20.30-08.30 hours). After an acclimatisation period of $7 \mathrm{~d}$ after the day of arrival, the rats were weighed and randomly put into three treatment groups $(n 6)$.

The present experiment adhered to the guidelines provided by the ASAB Ethical Committee for the use of animals in research (Anim Behav (1993), 45, 209-212) and the Canadian Council on Animal Care (Guide to the Care and Use of Experimental Animals), 2nd ed., vol. 2 (1993); 1st ed., vol. 1 (1984). All procedures were in compliance with the European Community Council Directive of 24 November 1986 (86/609/EEC).

\section{Materials}

The FOB was composed of a transparent observation cage, a grip strength apparatus, a suspension device, an open field, a startle apparatus, a tactile stimulation stylet and a digital thermometer that allowed taking rectal temperature of the rats. 
For the study of the cognitive performances, a light extinction test apparatus $\left(\right.$ TESLA $^{\mathrm{TM}}$; Open-System, France) was employed.

\section{Products}

The diets of treated rats were composed by adding 5 or $10 \%$ of oligofructose-enriched inulin (OEID-5\% or OEID-10\%) to the standard diet. Control rats received the standard diet. The diets were delivered ad libitum daily to rats during $14 \mathrm{~d}$.

\section{Procedures}

Functional observational battery. Two days before the treatment period, rats were tested using a FOB adapted from the procedures of Irwin (1968) and Rogers et al. (1997). Following the last day of treatment period, the rats were tested again using the same FOB.

The FOB employed was composed of three observation phases: a direct observation phase during which the animal was not disturbed, an active observation phase during which the animal was handled and tested, and a final phase during which the reactions of rats to different stimuli were observed. Numerous items concerning behavioural, neurological and physiological changes were recorded (Tables 1-4).

Light extinction test. The light extinction test apparatus (Messaoudi et al. 1996, 1999; Benton et al. 2003) consisted of a brightly lit cage $(50 \mathrm{~cm} \times 40 \mathrm{~cm} \times 37 \mathrm{~cm})$. The light level in the test cage was 1200 lux. Two levers were included in the device: an active lever that allowed access to a 30s period of darkness when pressed during light and an inactive lever that did not

Table 1. Effects of oligofructose-enriched diet (5 and $10 \%, w / w)$ in the functional observational battery on day 15

\begin{tabular}{|c|c|c|c|}
\hline Items & Control & OEID-5\% & OEID-10\% \\
\hline Rectal temperature & - & NS & NS \\
\hline \multicolumn{4}{|l|}{ Locomotor activity } \\
\hline $\begin{array}{l}\text { Number of squares } \\
\text { crossed in open-field }\end{array}$ & - & NS & More $(P<0.05)$ \\
\hline $\begin{array}{l}\text { Number of rearings } \\
\text { in open-field }\end{array}$ & & NS & NS \\
\hline Awakening/sleeping & Awake & Awake & Awake \\
\hline $\begin{array}{l}\text { Interest for a } \\
\text { presented object }\end{array}$ & - & NS & More $(P<0.05)$ \\
\hline Alley locomotor activity & - & NS & NS \\
\hline Finger approach & - & NS & NS \\
\hline Tail pinch & - & NS & NS \\
\hline Hindpaw pinch & - & NS & Less $(P<0.05)$ \\
\hline Touch escape & - & NS & NS \\
\hline Palpebral reflex & Normal & Normal & Normal \\
\hline Righting reflex & - & NS & NS \\
\hline Grip strength & - & NS & NS \\
\hline Visual placing & Normal & Normal & Normal \\
\hline Suspension test & - & NS & NS \\
\hline Startle response & - & NS & NS \\
\hline Respiratory rate & - & NS & NS \\
\hline Heart rate & - & NS & NS \\
\hline Aggressiveness & None & None & None \\
\hline Tremors & None & None & None \\
\hline Head twitching & None & None & None \\
\hline Body tone & - & NS & More $(P<0.07)$ \\
\hline Audible vocalisations & - & NS & NS \\
\hline
\end{tabular}

OEID, oligofructose-enriched inulin; NS, not significant $v$. control group $(P>0.10)$; None, behaviour not expressed by rats; More, significantly higher than control group; Less, significantly lower than control group; statistics: Kruskal-Wallis test and MannWhitney test.
Table 2. Effects of oligofructose-enriched diet (5 and $10 \%, w / w)$ in the functional observational battery on day 15

\begin{tabular}{lccc}
\hline Items & Control & OEID-5\% & OEID-10\% \\
\hline Defecation & - & NS & NS \\
Urination & - & NS & NS \\
Convulsions & None & None & None \\
Grooming & - & NS & NS \\
Nervousness & - & NS & NS \\
Piloerection & None & None & None \\
Erection/ejaculation & None & None & None \\
Lacrimation & None & None & None \\
Provoked freezing & None & None & None \\
Light pupil response & Normal & Normal & Normal \\
Bruxism & - & Less & Less \\
& & $(P<0.01)$ & $(P<0.01)$ \\
Bizarre behaviours & None & None & None \\
Death & None & None & None \\
\hline
\end{tabular}

OEID, oligofructose-enriched inulin; NS, not significant $v$. control group $(P>0.10)$; None, behaviour not expressed by rats; More, significantly higher than control group; Less, significantly lower than control group; statistics, Kruskal-Wallis test and MannWhitney test.

provide darkness. The same day, just after the last FOB, the rats were tested in the light extinction test in order to assess the effects of the oligofructose-enriched inulin on learning. During the test session, the rats were placed individually in the device for $15 \mathrm{~min}$ to learn to control the light. The number of active and inactive lever pressings was recorded.

\section{Statistics}

All the quantitative results were analysed using the KruskalWallis test followed by the Mann-Whitney test to compare treated groups with control. The Wilcoxon test was used to compare the first FOB items to those of the second FOB, and in the light extinction test to compare the active lever pressings with the inactive ones to determine the discrimination of the active lever from the inactive lever.

Data are reported as mean (SEM). Differences are considered to be significant at $P<0 \cdot 05$.

All the statistical analyses were carried out using Statview ${ }^{\circledR} 5$ (SAS Institute, Inc., Cary, NC, USA).

\section{Results}

Fuctional observational battery: comparison of treated groups with control group (Tables 1 and 2)

Before the treatment period, the Kruskal-Wallis test did not show significant differences among all the items of the FOB.

On day 15, at the end of the treatment period, the KruskalWallis test showed significant differences in various items of the FOB. The Mann-Whitney test showed the cases in which treated groups were significantly different from control:

- Locomotor activity (number of squares crossed in open-field): the locomotor activity of OEID-10\%-treated rats was significantly greater than that of control rats.

- Interest to a presented object: OEID-10\%-treated rats were significantly more interested by presented object than control rats.

- Hindpaw pinch: OEID-10\%-treated rats were significantly less reactive to the hindpaw pinch stimulation than control rats. 
Table 3. Effects of oligofructose-enriched diet (5 and 10\%, w/w) on change of studied items between FOB 1 and FOB 2

\begin{tabular}{|c|c|c|c|}
\hline Items & Control & OEID-5\% & OEID-10\% \\
\hline $\begin{array}{l}\text { Rectal temperature } \\
\text { Locomotor activity: }\end{array}$ & Increase $(P=0.10)$ & NS & Decrease $(P<0.08)$ \\
\hline Number of squares crossed in open-field & NS & NS & Increase $(P<0.05)$ \\
\hline Number of rearings in open-field & NS & NS & NS \\
\hline Awakening/sleeping & Awake & Awake & Awake \\
\hline Interest for presented object & Decrease $(P<0.08)$ & NS & Increase $(P<0.08)$ \\
\hline Alley locomotor activity & NS & NS & NS \\
\hline Finger approach & NS & NS & Decrease $(P<0.05)$ \\
\hline Tail pinch & NS & NS & NS \\
\hline Hindpaw pinch & NS & NS & Decrease $(P<0.06)$ \\
\hline Touch escape & NS & NS & NS \\
\hline Palpebral reflex & Normal & Normal & Normal \\
\hline Righting reflex & Decrease $(P<0.08)$ & Decrease $(P<0.05)$ & Decrease $(P<0.05)$ \\
\hline Grip strength & Decrease $(P<0.05)$ & Decrease $(P=0.10)$ & Decrease $(P<0.05)$ \\
\hline Visual placing & Normal & Normal & Normal \\
\hline Suspension test & NS & NS & NS \\
\hline Startle response & NS & NS & Decrease $(P<0.05)$ \\
\hline Respiratory rate & NS & NS & NS \\
\hline Heart rate & NS & NS & NS \\
\hline Aggressiveness & None & None & None \\
\hline Tremors & None & None & None \\
\hline Head twitching & None & None & None \\
\hline Body tone & NS & Increase $(P<0.08)$ & Increase $(P<0.05)$ \\
\hline Audible vocalisations & NS & NS & NS \\
\hline
\end{tabular}

FOB: functional observational battery; OEID, oligofructose-enriched inulin; NS, not significant between FOB 1 and FOB 2 in each group ( $P>0.10)$; None, behaviour not expressed by rats; statistics: Wilcoxon test FOB $1 v$. FOB 2.

Table 4. Effects of oligofructose-enriched diet (5 and 10\%, w/w) on change of studied items between FOB 1 and FOB 2

\begin{tabular}{lccc}
\hline Items & Control & OEID-5\% & OEID-10\% \\
\hline Defecation & NS & NS & NS \\
Urination & $\begin{array}{c}\text { Decrease } \\
(P<0.05)\end{array}$ & NS & NS \\
Convulsions & None & None & None \\
Grooming & NS & NS & NS \\
Nervousness & NS & Decrease & Decrease \\
& & $(P<0 \cdot 08)$ & $(P<0 \cdot 06)$ \\
Piloerection & None & None & None \\
Erection/ejaculation & None & None & None \\
Lacrimation & None & None & None \\
Provoked freezing & None & None & None \\
Light pupil response & Normal & Normal & Normal \\
Bruxism & Increase & NS & NS \\
Bizarre behaviours & $(P<0.05)$ & & None \\
Death & None & None & None \\
\hline
\end{tabular}

FOB, functional observational battery; OEID, oligofructose-enriched inulin; NS, not significant between FOB 1 and $F O B 2$ in each group $(P>0.10)$; None: behaviour not expressed by rats; statistics, Wilcoxon test FOB 1 vs. FOB 2 .

- Body tone: the muscular tone of OEID-10\%-treated rats tended to be more important than that of control rats.

- Audible vocalisations: no differences were observed between treated rats and control ones.

- Bruxism: OEID-5\%- and OEID-10\%-treated rats showed significantly less bruxism than control rats.

Functional obsertational battery change of studied items over time (Tables 3 and 4)

The Wilcoxon test showed significant changes in some items between the initial FOB, before the beginning of treatment, and the second FOB, after $14 \mathrm{~d}$ of OEID-5\% and OEID-10\% administration.
- Rectal temperature: rectal temperature of OEID-10\%-treated rats tended to decrease after the treatment period.

- Locomotor activity: OEID-10\%-treated rats were significantly more active during FOB 2 than during FOB 1 . The locomotor activity of the other rats remained stable between the two tests.

- Interest to a presented object: OEID-10\%-treated rats tended to be more interested by a presented object during FOB 2 than during FOB 1. Control rats tended to be less interested by a presented object during FOB 2 than during FOB 1.

- Finger approach: the reaction of OEID-10\%-treated rats was significantly less important during FOB 2 than during FOB 1. Control and OEID-5\%-treated rats showed the same behaviour during the two test sessions.

- Hindpaw pinch: the reaction of OEID-10\%-treated rats tended to be lower during FOB 2 than during FOB 1. Control rats showed the same reaction during the two test sessions.

- Righting reflex: OEID-5- and OEID-10\%-treated rats showed a faster righting reflex during FOB 2 than during FOB 1. Control rats tended to exhibit a slower righting reflex during FOB 2 than during FOB 1.

- Grip strength: control and OEID-10\%-treated rats gripped significantly less during FOB 2 than during FOB 1. OEID$5 \%$-treated rats tended to grip less during FOB 2 than during FOB 1.

- Startle response: OEID-10\%-treated rats showed significantly less reaction during FOB 2 than during FOB 1. No change in the startle response was observed in the other groups between the two test sessions.

- Body tone: the body tone of OEID-10\%-treated rats was significantly higher during FOB 2 than during FOB 1 . OEID-5\%-treated rats tended to be more tonic during FOB 2 than during FOB 1 . The body tone of control rats did not change between the two test sessions. 
- Audible vocalisations: the audible vocalisations of the three groups did not show significant change between the two test sessions.

- Defecation: the defecation of the rats of the three groups did not significantly change between the two test sessions.

- Urination: control rats showed significantly less urination during FOB 2 than during FOB 1. Urination of OEID-5\%and OEID-10\%-treated rats did not change between the two test sessions.

- Nervousness: the nervousness of control rats did not change between the two test sessions.

- Bruxism: control rats showed significantly more bruxism during FOB 2 than during FOB 1. OEID-5\%- and OEID$10 \%$-treated rats did not show any significant change in this behaviour between the two test sessions.

\section{Light extinction test}

Effects of the products on total lever-pressing activity. The Kruskal-Wallis test $\left(H_{\mathrm{df}=2}=3 \cdot 51\right.$; NS) did not show a statistical heterogeneity among the total lever pressings of the rats of control, OEID-5 \% and OEID-10\% groups (23.0 (SEM 9.1), 24.5 (SEM 3.6) and 30.0 (SEM 4.4), respectively). However, the total lever pressings of rats of the OEID-10\% group tended to be greater than that of control rats (Mann-Whitney test: $U=8 ; P=0 \cdot 10$ ).

Effects of the products on learning discrimination. The Wilcoxon test showed that OEID-5\%- and OEID-10\%-treated rats significantly discriminated the active lever from the inactive one $(z=2.02 ; P<0.05$ and $z=2.03 ; P<0.05$, respectively).

Control rats did not discriminate the active lever from the inactive one ( $z=0.42$; NS; Fig. 1).

\section{Conclusion}

The behavioural and cognitive effects of oligofructose-enriched inulin at the doses of 5 and $10 \%$ in the diet, orally ingested daily during 2 weeks, were investigated using a FOB and the light extinction test in male Wistar rats. Control rats received a standard diet and were tested in the same test situations. The behavioural effects were assessed $2 \mathrm{~d}$ before and $14 \mathrm{~d}$ after the beginning of the treatment period and the cognitive effects were investigated after the administration period by lever-pressing activity and learning discrimination, using the light extinction test paradigm. In our experimental conditions, on the basis of some significant results found using a FOB, it could be concluded that oligofructose-enriched inulin at the dose of $5 \%$ in the diet, orally ingested daily during 2 weeks, and particularly at $10 \%$ in the diet, showed relaxing-like effects, increased the general activity, stimulated the interest of the rats to their

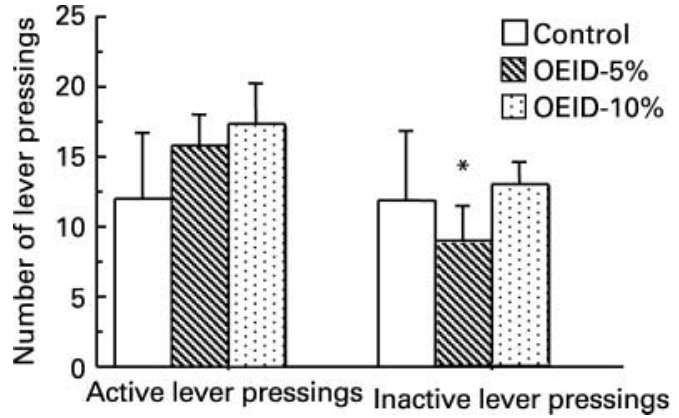

Fig. 1. Effects of oligofructose-enriched diet (5 and $10 \%$, w/w) on learning discrimination. Values are means with SEM shown by vertical bars. OEID, oligofructose-enriched inulin. Wilcoxon test: ${ }^{*} P<0.05$ (active lever pressings $v$. inactive lever pressings in each group).

environment and showed significant effects on learning discrimination in male rats in the light extinction test. Although the underlying mechanisms are still unknown, it appears that oligofructoseenriched inulin can benefit well-being and cognitive performances in rats.

\section{Acknowledgement}

This work was supported by ORAFTI Group, Tienen, Belgium.

\section{References}

Benton D, Ruffin M-P, Lassel T, Nabb S, Messaoudi M, Vinoy S, Desor D \& Lang V (2003) The delivery rate of dietary carbohydrates affects cognitive performance in both rats and humans. Psychopharmacology 166, 86-90.

Franck A (2002) Technological functionality of inulin and oligofructose. Br J Nutr 87, S283-S286.

Irwin S (1968) Comprehensive observational assessment: 1a. A systematic, quantitative procedure for assessing the behavioral and physiological state of the mouse. Psychopharmacologia (Berl) 13, 222-257.

Messaoudi M, Tricoire A, Lalonde R, Canini F \& Minn A (1996) Effects of MPTP on lever-pressing for light extinction in rats. Eur J Pharmacol 299, 17-20.

Messaoudi M, Desor D, Grasmück V, Joyeux M, Langlois A \& Roman FJ (1999) Behavioral evaluation of visceral pain in a rat model of colonic inflammation. Neuroreport 10, 1137-1141.

Roberfroid MB (1999) Concepts in functional foods: the case of inulin and oligofructose. J Nutr 129, 1398S-1401S.

Rogers DC, Fisher EMC, Brown SDM, Peters J, Hunter AJ \& Martin JE (1997) Behavioral and functional analysis of mouse phenotype: SHIRPA, a proposed protocol for comprehensive phenotype assessment. Mamm Genome 8, 711-713. 